\title{
Consumers' Willingness to Buy CRISPR Gene-Edited Tomatoes: Evidence from a Choice Experiment Case Study in Germany
}

\author{
Linde Götz ${ }^{1,2, *}$, Miranda Svanidze ${ }^{1}$, Alain Tissier ${ }^{3}$ and Alejandro Brand Duran ${ }^{3}$ \\ 1 Department Agricultural Markets, Marketing and World Agricultural Trade, Leibniz Institute of Agricultural \\ Development in Transition Economies (IAMO), 06120 Halle, Germany; svanidze@iamo.de \\ 2 Institute of Agricultural and Nutritional Sciences, Martin Luther University Halle-Wittenberg, \\ 06108 Halle, Germany \\ 3 Department of Cell and Metabolic Biology, Leibniz Institute of Plant Biochemistry (IPB), \\ 06120 Halle, Germany; alain.tissier@ipb-halle.de (A.T.); Alejandro.BrandDuran@ipb-halle.de (A.B.D.) \\ * Correspondence: goetz@iamo.de; Tel.: +49-345-2928-327
}

Citation: Götz, L.; Svanidze, M.;

Tissier, A.; Brand Duran, A.

Consumers' Willingness to Buy CRISPR Gene-Edited Tomatoes: Evidence from a Choice Experiment Case Study in Germany. Sustainability 2022, 14, 971. https://doi.org/ $10.3390 /$ su14020971

Academic Editors:

Konstadinos Mattas,

George Baourakis and Stefanos

A. Nastis

Received: 30 November 2021

Accepted: 5 January 2022

Published: 15 January 2022

Publisher's Note: MDPI stays neutral with regard to jurisdictional claims in published maps and institutional affiliations.

Copyright: (c) 2022 by the authors. Licensee MDPI, Basel, Switzerland. This article is an open access article distributed under the terms and conditions of the Creative Commons Attribution (CC BY) license (https:/ / creativecommons.org/licenses/by/ $4.0 /)$.

\begin{abstract}
The CRISPR gene-editing (GE) breeding method is used to increase the resilience of highyielding tomato cultivars against pests and diseases, reducing crop protection requirements. This study investigated consumers' willingness to buy CRISPR GE tomatoes in a repeated discrete-choice experiment. We observed a strong positive effect of providing information on the CRISPR breeding technology, while the sensory experience of the CRISPR GE tomatoes in a visit to a greenhouse had a rather weak, predominantly negative effect on the participants' willingness to buy CRISPR GE tomatoes. We found that roughly half of the 32 participants demonstrated constant CRISPR GE tomato choices during the experiments, and these participants were mainly employed as scientists. However, the rest of the participants changed their CRISPR GE tomato choices, with the majority showing an increase in their willingness to buy CRISPR GE tomatoes; these "changers" were dominated by nonscientists. Science communication on CRISPR GE breeding technology should target people with little knowledge about the technology, and consumers of organic tomatoes seem to have more specified, stable preferences regarding the technology. Further, scientific information about the CRISPR GE methodology should preferentially be provided when new technology and information about it are not yet widespread and people have not yet formed a strong opinion about the technology.
\end{abstract}

Keywords: consumers' willingness to buy; discrete-choice experiment; CRISPR gene-edited tomatoes; information intervention; scientific communication

\section{Introduction}

Wild tomato species such as Solanum habrochaites or S. pennellii are known to suffer from fewer diseases and to be more resistant to pests than cultivated tomato (S. lycopersicum) varieties. The cultivated tomato varieties used in industrialized horticulture for tomato production around the world were bred to greatly increase yields. They have larger fruits and higher yields but are more susceptible to diseases. Apparently, however, in the course of breeding for increased yields, the activity of the genes responsible for producing certain defenses weakened or was lost. As a result, the cultivated tomatoes widespread in tomato production today require more intensive pesticide treatment [1].

One novel application in tomato breeding is the clustered regularly interspaced short palindromic repeats (CRISPR) gene-editing (GE) technology, which aims to re-activate or to integrate the appropriate genetic material in the high-yielding tomato cultivars and make them more resilient and resistant to pests and diseases [2]. Ultimately, these CRISPR GE tomato varieties should allow for a significant reduction in the application of cropprotection products in tomato cultivation. This would help contribute to the achievement of the EU's goal of reducing the use of and risk from chemical pesticides in the EU by $50 \%$ by 2030 [3], while still providing end consumers with sufficient tomato supplies. If the 
breeding efforts succeed in keeping yields constant, price increases for the end consumers might be small.

It should be pointed out that GE foods-similarly to transgenic genetically modified (GM) foods-are not available to end consumers on the retailers' shelves in Germany. Moreover, farmers do not plant crops of genetically engineered-i.e., GE or transgenic GM - seeds. In 2018, GE organisms were made subject to the EU legislation regarding GM organisms through a decision from the European Court of Justice [4].

In general, plant breeding involves the modification of genetic information, stored in the DNA of plants, regardless of whether traditional or modern methods are used. This can be performed by crossing different varieties with each other or even related wild species to allow for the introgression of alleles of interest from the wild relatives into the cultivated background. In addition, another widely used method is mutation breeding. This involves treating plant seeds with radioactive radiation or chemical substances, for example, or freezing seeds or subjecting them to a heat shock to induce a change in the plant's DNA. The disadvantage of mutation breeding is that it is not known in advance where and how much genetic material will be changed by the mutation and thus plants with new and desired mutations and properties but also a range of undesired mutations and properties can be created. The mutated varieties need to be back-crossed with an elite cultivar many times until the undesired traits are segregated away and a variety with only the desired traits emerges. This process is time-intensive and usually takes several years.

The GE breeding method, which was developed only a few years ago, makes it possible to precisely change-i.e., "edit" - the DNA of an organism. In contrast to traditional methods, the DNA is cut at a very specific point known to be responsible for a desired plant trait. A targeted mutation is induced with high precision and thus plants with undesired properties are rarely created. Therefore, the breeding process is finalized much more quickly. Although the DNA of a GE plant is altered, no foreign DNA is introduced as with GM plants. Thus, GE plants are not transgenic.

The application of the CRISPR technology for GE was spurred by the research by Charpentier and Doudna, who were awarded the Nobel Prize in Chemistry in 2020, which clarified the underlying mechanism of CRISPR [5]. The CRISPR method involves the use of a segment of ribonucleotide acid (RNA), the guide RNA (gRNA), to detect a specific point in the DNA sequence of the genome that encodes a specific trait. The Cas9 enzyme functions as a "genetic scissor" and cuts the DNA at the specified point. The double-strand break of the DNA triggers the DNA repair mechanism, which might induce a mutation such that the genome is changed irreversibly. The CRISPR system was originally discovered in bacteria, where it functions as a defense mechanism against viral pathogens [6].

Since GE is a relatively new technology, there are only a few gene-edited foods available on the market. For example, Sanatech has sold CRISPR-Cas9-modified tomatoes, which have a higher nutritional value due to their effects on blood pressure and stress reduction, in Japan since September 2021 [7]. This explains why existing research regarding consumers' acceptance of GE foods is limited.

Beghin et al. [8] have provided an overview of studies on consumer preferences for gene-edited food. They have indicated that due to the limited availability of GE food on the market, most of the reviewed studies are hypothetical, raising concerns about a hypothetical bias [9]. Comparing GE to transgenic GM foods, empirical evidence suggests that consumers in general prefer GE foods over GM foods to some degree [10-12]. Nonetheless, consumers often lack the knowledge to clearly distinguish GE from GM foods [13] and, therefore, without prior information, the distinction may not be made [14].

Thus, another strand of literature has investigated the effect of information on consumer acceptance of genetically engineered food, although the empirical findings are mixed. While Carrasson et al. [15], Dolgopolova et al. [16], Costa-Font et al. [17], and Boccaletti et al. [18] found that information increases the acceptance of genetically engineered food, Scott et al. [19], Rollin et al. [20] and McFadden and Lusk [21] indicated that providing new information does not improve consumers' attitudes towards genetically 
engineered food. Moreover, Yang and Hobbs [22] have explored the effect of different styles of communication on consumer choices. In particular, they found a stronger positive effect of narrative-style information compared to logical-scientific communication framing on consumer choices.

While there are several studies that have investigated the effect of information on consumer acceptance of genetically engineered food, to the best of our knowledge, very few studies have focused on the effect of sensory experience. One exception is the study by Grunert et al. [23], which found that consumers with a positive tasting experience had fewer negative attitudes towards cheese they believed was produced using a GM starter culture. However, consumer studies have been extensively conducted with regards to the sensory experiences of non-GM products [24-26]. For example, Kallas et al. [24] investigated the role of food neophobia in consumers' valuation of innovative food products by accounting for sensory experience. They found that consumers who were more reluctant to eat new foods also had a lower willingness to pay for food with an innovative trait. Moreover, food traits such as "organic" and "low greenhouse emissions" contributed to a higher willingness to pay among consumers in Spain and the UK [27].

Using a discrete choice experiment, this study aims to investigate consumers' willingness to buy tomatoes produced from GE plants that were bred by the CRISPR method. Discrete choice experiments are often used when data on consumer behavior cannot be obtained because the respective product is not yet offered on the market and thus the revealed preferences approach cannot be pursued [28]. Discrete choice experiments build on the random utility theory, which assumes that consumers draw utility from the attributes of the goods. Two choice options differ in the level of at least one attribute; thus, a consumer chooses the option from a choice set which provides the highest utility to him or her [29].

We focus on the following research questions: Are consumers willing to buy tomatoes produced from GE plants? Apart from identifying the willingness to buy within a choice experiment case study, we analyze the role of information intervention and sensory experience in the observed consumer behavior towards CRISPR GE tomatoes. Do participants' choices change if information on the CRISPR breeding technology is provided? Does a sensory experience, such as the inspection of CRISPR GE tomato plants in a greenhouse laboratory, influence consumers' attitudes towards GE tomatoes? It should be pointed out that the sensory experience in this experiment included inspecting and touching the CRISPR GE tomato plant and tomato fruit. The CRISPR GE tomato plants presented in the greenhouse originated from breeding efforts that were aimed at the development of a tomato cultivar that would be more resistant and resilient to diseases and pests so that fewer pesticide treatments would be necessary. Furthermore, we aimed to analyze whether changes in consumer preferences were persistent or whether they might indeed change or become more well-defined during the repeated choice experiment. We therefore repeated the choice experiment after a period of one week.

We hypothesize that the information and sensory experience of the CRISPR GE tomatoes during a greenhouse visit increases the number of participants choosing CRISPR GE tomatoes in the choice experiment, reflecting an increase in consumers' willingness to buy CRISPR GE tomatoes. The choice experiment is supplemented by a questionnaire, which, in addition to socioeconomic and demographic traits, focuses on factors that could potentially influence the willingness to buy CRISPR GE tomatoes.

Following a case study approach, this study is of an exploratory nature, meaning the quantitative analyzability and the generalizability of results to a population are limited [4] Due to the spread of the COVID-19 pandemic, hygiene and distancing rules had to be applied, which limited the number of people participating in this study, particularly since the study design included a visit to a greenhouse laboratory. Finally, the spread of the pandemic limited the acquisition of participants due to movement restrictions put in place by the government.

Our research hypothesis is only partially supported by the study results. We found that providing information about the CRISPR breeding technology strongly increased the 
participants' willingness to buy CRISPR GE tomatoes. However, the sensory experience of inspecting and touching CRISPR GE tomatoes during a greenhouse visit decreased the number of CRISPR GE tomato choices, although to a moderate degree. According to our results, participants whose preferences towards CRISPR GE tomatoes changed over the experiment were dominated by non-scientists, while the respondents with constant preferences for CRISPR GE tomatoes were mainly employed as scientists. This result points towards the potential importance of knowledge about the new technology in order for it to be accepted.

\section{Materials and Methods}

The choice experiment of this study was composed of 4 choice sets with 3 choice options each. Each choice option represented a package of tomatoes that was characterized by 4 attributes, i.e., the breeding technology, production process, pesticide level, and the price (Table 1). Generally speaking, option 1 corresponded with conventional tomatoes, option 2 represented organic tomatoes, and the hypothetical option 3 covered tomatoes grown from seeds that were bred using the CRISPR GE method.

Table 1. Characteristics of the choice options.

\begin{tabular}{ccc}
\hline Attributes & Levels & Compatibilities \\
\hline breeding technique & traditional; CRISPR GE & $\begin{array}{c}\text { option 1: traditional } \\
\text { option 2: traditional } \\
\text { option 3: CRISPR GE } \\
\text { option 1: conventional } \\
\text { option 2: organic } \\
\text { production process }\end{array}$ \\
option 3: conventional \\
option 1: average \\
pesticide level & conventional; organic & option 2: half of average \\
& average; half of average & option 3: average; half of average \\
price per package & EUR 3.50; EUR 2.50; EUR & option 2: EUR 3.50 \\
& 1.50 & option 3: EUR 2.50; EUR 1.50 \\
\hline
\end{tabular}

More specifically, option 1 represented a package of tomatoes produced from plants bred by traditional breeding techniques that was grown within a conventional tomato production system meeting average standard pesticide level and having a price of EUR 2.50/package. Option 2 depicted a package of tomatoes produced from plants bred by traditional breeding techniques grown in an organic production system with only half of the average amount of chemical pesticides typically applied for tomatoes and offered at a price of EUR 3.50/package. Hypothetical option 3 presented a package of tomatoes produced from plants grown from seeds bred with CRISPR GE technology and conventionally grown, while the pesticide levels and the price varied between the choice sets. In particular, for choice sets 1 and 2, the pesticide level of option 3-similar to option 1-was an average amount, while for choice sets 3 and 4-similar to option 2-it amounted to only half of the average amount of pesticides used in tomato production. Similar to option 1, the price for the tomato package in option 3 for choice sets 1 and 3 was EUR 2.50/package, while a lower price (EUR 1.50) for choice sets 2 and 4 was used.

We did not consider an opt-out option among the choices even though it would have made the experimental choice situation more similar to a real buying situation in a supermarket. Sometimes, however, participants may select the opt-out option to avoid a choice between homogeneous options [30,31]. By excluding an opt-out option, the respondents were forced to choose one option out of the three in each choice set, assuming they had a clear preference.

The questionnaire was designed to identify the factors influencing the willingness to buy CRISPR GE tomatoes utilizing the theoretical model by Farid et al. [32]. Specifically, questions were targeted at identifying the participants' knowledge, attitudes, perceived 
benefits, perceived risk, and trust in the CRISPR technology and the willingness to buy CRISPR GE tomatoes. The follow-up questionnaire was of a similar design and was intended to highlight whether any of the possible influencing factors might have changed.

This choice experiment with the 4 choice sets (see Appendix A, Table A1) was conducted 4 times to elicit consumer willingness to buy CRISPR GE tomatoes: (a) without prior intervention, (b) after the provision of information, (c) following a greenhouse visit, and (d) within a follow-up experiment (Figure 1). Participation was limited by the precondition to eat and buy tomatoes regularly.

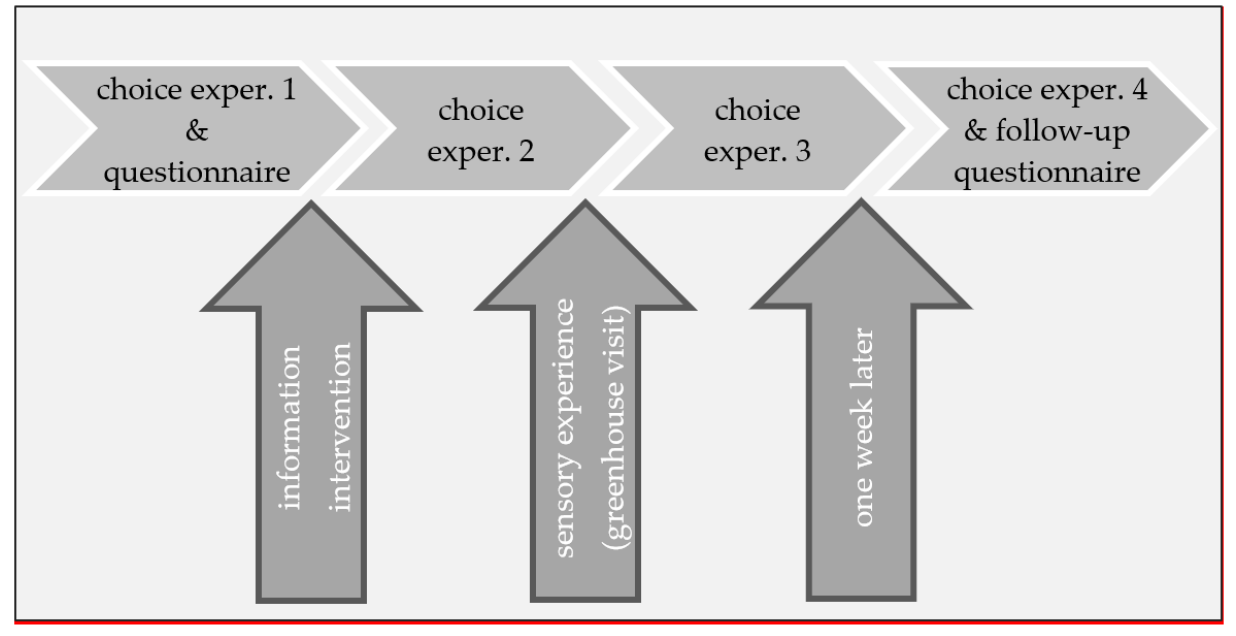

Figure 1. Set-up of the choice experiments.

In the first choice experiment, the participants were asked to directly fill in the questionnaire and the choice experiment without any prior information about the CRISPR GE tomatoes. In the second-choice experiment ("information intervention"), information on the CRISPR GE breeding method was provided orally before the participants were asked to fill in the choice experiment again.

After the completion of the second choice experiment, participants were taken to a greenhouse laboratory at the Leibniz Institute for Plant Biochemistry (IPB) in Halle (Germany) for a visual and tactile sensory experience with the CRISPR GE tomatoes for the third choice experiment ("sensory experience intervention"). After the greenhouse visit, participants were asked to fill in the choice experiment for the third time. One week later, the respondents filled in the choice experiment again and a shortened version of the questionnaire in the fourth-choice experiment ("follow-up experiment/survey") which aimed to verify any changes in choices, especially concerning the CRISPR GE tomatoes, over time. Changes in choices would indicate whether consumer preferences might have changed due to the information and sensory experience intervention.

During the "information intervention", participants were given an oral explanation of the changes induced by traditional plant breeding in general and the CRISPR GE plant breeding method in particular. The difference between the two genetic breeding methods of GE and transgenic GM was explained and examples of the advantages of CRISPR GE crops were provided. In addition, participants were introduced to the CRISPR breeding efforts for tomatoes through an explanation of the background of why they were created, and the research aims for CRISPR breeding technology [2].

Within the scope of "sensory experience", the respondents were encouraged to inspect and touch the traditionally bred tomato and the CRISPR GE tomato plants in order to check whether any differences could be recognized. In the greenhouse laboratory, additional information on the CRISPR method was provided and questions by the participants were answered by a senior scientist. It should be pointed out that, unlike Grunert et al.'s [23] research, the CRISPR GE tomato plants presented in the greenhouse did not offer a direct extra benefit to the participants. Especially since the breeding experiment was still ongo- 
ing, the CRISPR GE tomato plants did not yet require fewer pesticides compared to the traditionally bred tomato varieties. In addition, the presented tomato plants were being grown for research purposes; thus, they were about two meters tall with many large leaves and only a few tomato fruits.

Participants in the choice experiment were selected using the method of convenience sampling. People who could be contacted easily and whose participation could be organized under the COVID-19 pandemic conditions were gathered. This sampling method enabled us to conduct the survey despite the strict distance and hygiene rules applied during the outbreak of the COVID-19 pandemic.

Because of the small number of participants, we consider this choice experiment as a case study. Thus, the survey and choice experiment results were not evaluated quantitatively but rather qualitatively, e.g., by comparing the number of cases within the study [33]. While these results cannot be generalized to the population, they might provide valuable insights that could guide and justify the design of future data collection efforts [34].

\section{Results}

Data on 32 participants were gathered in November 2020 at the IPB in Halle, Germany [35]. The participants' ages varied between 19 and 56 years with an equal share of men and women. With $41 \%$ of the respondents holding a university degree and $31 \%$ having a $\mathrm{PhD}$, the educational level of the respondents was particularly high and above the average in Germany. Similarly, with 14 (44\%) of the respondents employed as scientists and 17 $(53 \%)$ as non-scientists, the share of scientists in the sample was above average. This special characteristic of the sample opened up an opportunity to pay particular attention to the possible influence of knowledge on the stated choices despite the small size of the sample.

The data gathered within the questionnaire show that the participants' knowledge of the CRISPR method was limited, but $94 \%$ stated they had an interest in learning more about genetic engineering in the food sector. Overall, the results reveal a positive attitude, trust, perceived benefits, and a willingness to purchase GE foods among the majority of the respondents.

The CRISPR GE tomato choices for the sample of the 32 participants are presented for each experiment by choice set in Table 2. It is striking that in the overall first choice set (experiment 1) no participant chose a single CRISPR GE tomato package. In each experiment, a similar pattern of CRISPR GE tomato choices through the choice sets unfolded. In particular, the number of CRISPR GE tomato choices was higher for choice set 2 compared to set 1 in all four experiments. We trace this back to the reduced price of the CRISPR GE tomatoes - to a level below the price of a conventional tomato package-in choice set 2 (reduced price effect). Even more participants chose the CRISPR GE tomatoes in choice set 3 in all four experiments when the CRISPR GE tomato pesticide requirement was reduced to a level similar to organic tomatoes (reduced pesticide requirement effect). The number of participants who chose CRISPR GE tomatoes was always highest in choice set 4 when the package of CRISPR GE tomatoes was cheapest and the pesticide requirement was reduced to a level similar to the organic tomato at the same time (reduced price and pesticide requirement effect). Overall, amounting to 65 , the total number of CRISPR GE tomato packages chosen was highest for experiment 2 after the information intervention, which was followed by experiment 4 after the "follow-up survey" with 62 and experiment 3 after the "greenhouse visit" intervention with 59 CRISPR GE tomato packages chosen. With 45 tomato packages chosen, the preference for CRISPR GE tomatoes was lowest in experiment 1 without any intervention. The observed overall CRISPR GE tomato choices resulted from 25 respondents, who chose CRISPR GE tomatoes at least once throughout the four choice experiments. Overall, 25 respondents chose CRISPR GE tomatoes at least once throughout the four choice experiments, while seven participants did not choose any CRISPR GE tomato package at all. 
Table 2. CRISPR GE tomato choices per choice set and experiment.

\begin{tabular}{ccccc}
\hline & Exp. 1 & Exp. 2 & Exp. 3 & Exp. 4 \\
\hline choice set 1 & 0 & 5 & 5 & 4 \\
choice set 2 & 9 & 15 & 14 & 15 \\
choice set 3 & 15 & 20 & 18 & 20 \\
choice set 4 & 21 & 25 & 22 & 23 \\
\hline total & 45 & 65 & 59 & 62 \\
\hline
\end{tabular}

The changes in the CRISPR GE tomato choices throughout the four experiments are depicted in Table 3. Following the information intervention after experiment 1, an additional five, six, six, and four CRISPR GE tomato packages were chosen in choice sets $1,2,3$, and 4 , respectively, compared to experiment 1 . These changes resulted from 11 participants preferring the CRISPR GE tomato package at least once in experiment 2, while only one participant chose one less package of CRISPR GE tomatoes. In contrast, after the greenhouse visit, we observed only two CRISPR GE tomato packages chosen by two additional participants in experiment 3 , while seven respondents chose fewer than eight CRISPR GE tomato packages. In the fourth-choice experiment, which was conducted one week after the third-choice experiment, we observed an increase in CRISPR GE tomato choices by three in total resulting from five CRISPR GE tomato choices more among four respondents, while two respondents preferred fewer CRISPR GE tomatoes. It should be pointed out that three of the four respondents with increasing CRISPR GE tomato choices in experiment 4 had decreased their CRISPR GE tomato choices in the previous experiment 3.

Table 3. CRISPR GE tomato choices and their change per choice set and experiment.

\begin{tabular}{|c|c|c|c|c|c|c|c|}
\hline & $\begin{array}{c}\text { Choices } \\
\text { Exp. } 1\end{array}$ & \multirow{6}{*}{ 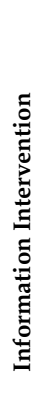 } & $\begin{array}{l}\text { Change Choices } \\
\text { Exp. } 2 \\
\text { Compared to } \\
\text { Exp. } 1\end{array}$ & \multirow{5}{*}{ 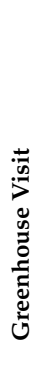 } & \multirow{2}{*}{$\begin{array}{l}\text { Change Choices } \\
\text { Exp. } 3 \\
\text { Compared to } \\
\text { Exp. } 2\end{array}$} & \multirow{6}{*}{ 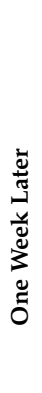 } & $\begin{array}{l}\text { Change Choices } \\
\text { Exp. } 4 \\
\text { Compared to } \\
\text { Exp. } 3\end{array}$ \\
\hline $\begin{array}{l}\text { choice } \\
\text { set } 1\end{array}$ & 0 & & +5 & & & & -1 \\
\hline $\begin{array}{l}\text { choice } \\
\text { set } 2\end{array}$ & 9 & & +6 & & -1 & & $+2 /-1$ \\
\hline $\begin{array}{c}\text { choice } \\
\text { set } 3\end{array}$ & 15 & & $+6 /-1$ & & $+1 /-3$ & & +2 \\
\hline $\begin{array}{l}\text { choice } \\
\text { set } 4\end{array}$ & 21 & & +4 & & & & +1 \\
\hline total & 45 & & +20 & & -6 & & +3 \\
\hline
\end{tabular}

From an overall perspective, we found that more CRISPR GE tomatoes were chosen in experiment 4 compared to experiment 1 in each choice set. More specifically, four, six, five, and two more CRISPR GE tomato packages were selected in choice sets 1, 2, 3, and 4 of experiment 4 , respectively, summing up to an additional 17 CRISPR GE tomato packages in total.

We identified 17 respondents who changed their CRISPR GE tomato choices in experiment 4 compared to experiment 1 , with one to six changes in CRISPR GE tomato choices each. Among the changers, 13 participants $(41 \%)$ chose more, and 4 respondents $(13 \%)$ chose fewer CRISPR GE tomatoes (Figure 2). However, the number of CRISPR tomato choices remained constant for 15 participants. It should be pointed out that 7 of the 15 participants with constant choices chose organic tomatoes in all 16 choice sets continuously. 


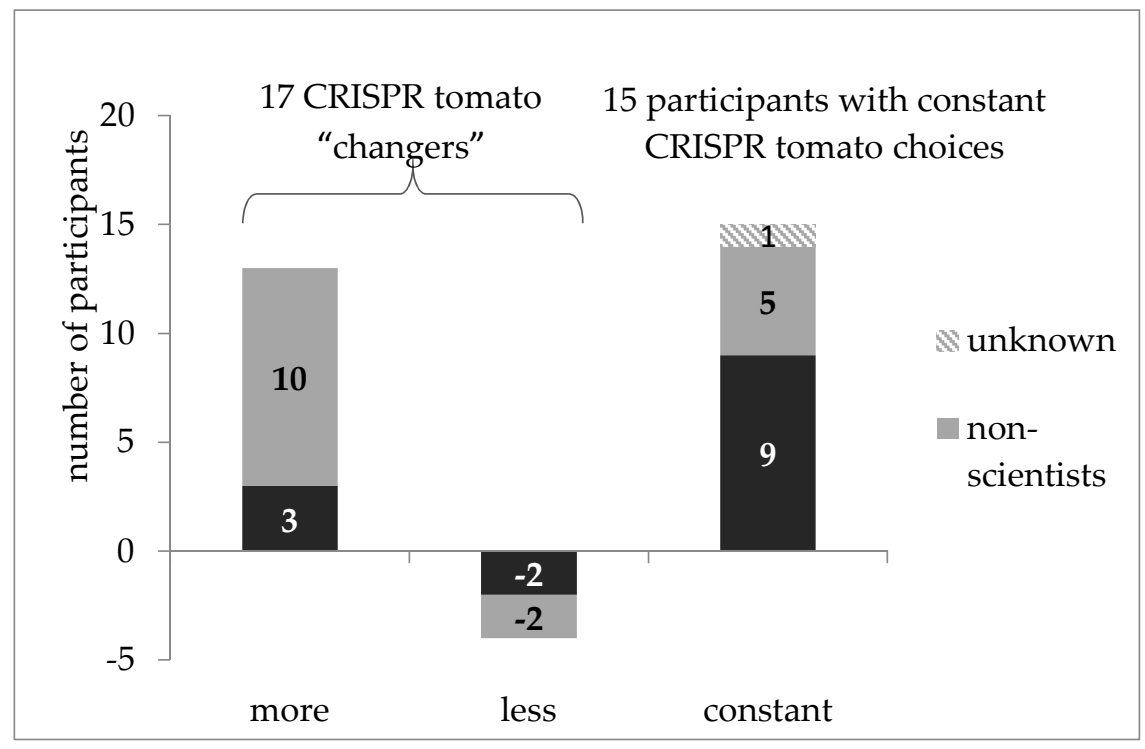

Figure 2. Overall change in CRISPR GE tomato choices.

To further evaluate the choices, we built on the special feature of our sample, i.e., that 14 respondents were employed as scientists and 17 as non-scientists, while one did not indicate the affiliation. We found that the majority of scientists (64\%) kept their CRISPR GE tomato choices unchanged, while the CRISPR GE tomato choices of the majority of the non-scientists $(71 \%)$ had changed in experiment 4 compared to experiment 1.

Moreover, the results of the repeated questionnaire filled in during the fourth experiment show that participants slightly lost trust in the CRISPR technology and assessed their own knowledge as lower compared to the first questionnaire on average. Furthermore, the assessment of the willingness to buy remained constant. This is in contrast to the results of the choice experiment, which indicated that the willingness to buy substantially increased, which was reflected in the 17 additional CRISPR GE tomato packages chosen and the 13 respondents with more CRISPR GE choices in experiment 4 compared to experiment 1 , while only four respondents had decreased their CRISPR GE choices.

\section{Discussion}

To summarize, CRISPR GE tomatoes were widely chosen throughout the choice experiments with its 16 choice sets. In particular, 25 out of the 32 participants chose a CRISPR GE tomato package at least once. This result confirms the positive attitude, trust, and perceived benefits stated by the majority of the respondents towards GE foods in the questionnaire. The CRISPR GE tomato choice pattern observed in each experiment suggests that the reduced pesticide amounts in the CRISPR GE tomatoes induced more participants to choose CRISPR GE tomatoes, and thus this is valued higher by consumers than a lower price.

We recognize that about half of the respondents changed their CRISPR GE choices during the experiments. In particular, an additional 17 CRISPR GE tomato packages were chosen in the fourth experiment compared to the first experiment, arising from 13 respondents increasing and 4 respondents decreasing their CRISPR GE tomato choices. The increased willingness to buy CRISPR GE tomatoes revealed in the choice experiments is not in line with the constant level of willingness to buy genetically engineered foods as stated in the questionnaire filled in during the first and the fourth experiment. We assume that the willingness to buy that was indirectly identified in the choice experiment better reflects consumers' actual preferences than a willingness to buy directly identified through self-assessment in the questionnaire.

However, the number of CRISPR GE tomatoes chosen varied throughout the experiments. We especially observed a strong positive effect of providing information on the 
CRISPR technology between choice experiments 1 and 2, leading to an increase in the CRISPR GE tomatoes chosen by 20 packages in experiment 2 . We observed, on the other hand, a rather weak, predominantly negative effect of the greenhouse visit, which resulted in a decrease in the chosen CRISPR GE tomatoes by six packages altogether in experiment 3. This result does not confirm our hypothesis that a sensory experience will increase a willingness to buy. We explain this finding as a result of the type of presentation about the CRISPR GE tomatoes in the greenhouse. As pointed out above (in Section 2), in a way different to Grunert et al. [23], the presentation of the tomatoes in the greenhouse did not make evident the actual but rather the potential additional benefits of the CRISPR GE tomatoes to the participants. In our study, breeding efforts were still ongoing and the breeding aims, that is, to make a high-yielding tomato variety more resilient against pathogens and pests, were not yet reached. In this regard, our results confirm the findings in the literature that genetically engineered foods are accepted more by consumers if they provide an extra benefit to them. Apart from the 17 respondents who changed their CRISPR GE tomato choices, the remaining 15 participants showed a constant number of CRISPR GE tomato choices. In particular, 7 out of the 15 participants with constant CRISPR GE tomato choices did not choose any CRISPR GE tomatoes throughout the experiments, but rather chose organic tomatoes in all 16 choice sets. This result may be interpreted as evidence for participants that prefer organic tomatoes to have more specified preferences regarding CRISPR GE tomatoes. It seems that the willingness to buy CRISPR GE tomatoes by people preferring organic tomatoes could not be influenced by information and a sensory experience/acquaintance with the technology.

The results of the choice experiments further reveal that the participants with constant CRISPR GE tomato choices were dominated by scientists (by 65\%), while 70\% of the respondents with changing CRISPR GE tomato choices were employed as non-scientists. Assuming that the scientists had more knowledge of the CRSIPR technology compared to non-scientists, these results could be interpreted as evidence that knowledge on the new technology is key for impacting preferences.

Our study results may be interpreted as evidence for the importance of providing information and opportunities to become acquainted with the technology to increase consumers' willingness to buy food from plants bred by CRISPR, which has also been confirmed in the existing literature [22,35]. Consumers of ecologically produced tomatoes seem to be less likely to change their willingness to buy GE tomatoes, and future research could test whether consumers of organic tomatoes have more specified preferences and well-defined opinions about CRISPR GE tomatoes.

\section{Conclusions}

Our findings serve to draw preliminary conclusions regarding the design of science communication. In general, science communication aims to provide information on and to familiarize the general public with new technologies. However, science communication should rather target people with little knowledge on the new technologies and who do not yet have well-defined preferences regarding the technology. Furthermore, the format of science communication should be well selected. Yang and Hobbs [22] have shown that information provided within a narrative form may be better suited for the public versus the logic-scientific form. When it comes to the timing of science communication, scientific information on the CRISPR methodology should be provided when the new technology and information thereof are not yet widespread, and thus people have not yet formed an opinion on the new technology beyond a general cautiousness against something unknown.

Nevertheless, the results of this case study should be interpreted with care. Due to the limited size of the sample, these results should not be generalized [6]. Despite that, the results of this case study can provide guidance for future research that would allow for a generalization of results if based on a larger sample size. Moreover, the factors determining the tomato choices could be investigated comprehensively within a quantitative analysis of the survey results in future research. 
Author Contributions: Conceptualization, L.G., M.S. and A.T.; methodology, L.G., M.S. and A.T. resources, A.T. and A.B.D., data management L.G.; writing-original draft preparation, L.G.; writingreview and editing, M.S., L.G., A.T. and A.B.D. All authors have read and agreed to the published version of the manuscript.

Funding: This research received no external funding.

Institutional Review Board Statement: The study was conducted in accordance with the Declaration of Helsinki, and approved by the Ethics Committee of IAMO (certificate reference number 03/2020, issued 6 November 2020).

Informed Consent Statement: Informed consent was obtained from all subjects involved in the study.

Data Availability Statement: Participants were guaranteed anonymity of the data they had provided. In addition, due to the small sample size, we confirmed that the data will not be shared with third parties.

Acknowledgments: We would like to thank the three anonymous reviewers for providing very helpful comments and suggestions to improve the manuscript. Moreover, we would like to thank all respondents for their time and willingness to participate in the choice experiment. Furthermore, we are grateful to T.D. for her research assistance to this project provided in the course of conducting her Master's thesis.

Conflicts of Interest: The authors declare no conflict of interest. This publication reflects only the authors' views.

\section{Appendix A}

Table A1. Design of the choice experiment.

\begin{tabular}{|c|c|c|c|}
\hline \multicolumn{4}{|c|}{ Choice set 1} \\
\hline \multirow{5}{*}{$\begin{array}{l}\text { Breeding technique } \\
\text { Production technique } \\
\text { Pesticide level } \\
\text { Price in EUR per } \\
\text { package }\end{array}$} & Option 1 & Option 2 & Option 3 \\
\hline & Traditional & Traditional & with CRISPR \\
\hline & Conventional & Organic & Conventional \\
\hline & Average & Half of average & Average \\
\hline & EUR 2.50 & EUR 3.50 & EUR 2.50 \\
\hline \multicolumn{4}{|c|}{ Choice set 2} \\
\hline \multirow{5}{*}{$\begin{array}{l}\text { Breeding technique } \\
\text { Production technique } \\
\text { Pesticide level } \\
\text { Price in EUR per } \\
\text { package }\end{array}$} & Option 1 & Option 2 & Option 3 \\
\hline & Traditional & Traditional & with CRISPR \\
\hline & Conventional & Organic & Conventional \\
\hline & Average & Half of average & Average \\
\hline & EUR 2.50 & EUR 3.50 & EUR 1.50 \\
\hline \multicolumn{4}{|c|}{ Choice set 3} \\
\hline \multirow{5}{*}{$\begin{array}{l}\text { Breeding technique } \\
\text { Production technique } \\
\text { Pesticide level } \\
\text { Price in EUR per } \\
\text { package }\end{array}$} & Option 1 & Option 2 & Option 3 \\
\hline & Traditional & Traditional & with CRISPR \\
\hline & Conventional & Organic & Conventional \\
\hline & Average & Half of average & Half of average \\
\hline & EUR 2.50 & EUR 3.50 & EUR 2.50 \\
\hline \multicolumn{4}{|c|}{ Choice set 4} \\
\hline \multirow{5}{*}{$\begin{array}{l}\text { Breeding technique } \\
\text { Production technique } \\
\text { Pesticide level } \\
\text { Price in EUR per } \\
\text { package }\end{array}$} & Option 1 & Option 2 & Option 3 \\
\hline & Traditional & Traditional & with CRISPR \\
\hline & Conventional & Organic & Conventional \\
\hline & Average & Half of average & Half of average \\
\hline & EUR 2.50 & EUR 3.50 & EUR 1.50 \\
\hline
\end{tabular}




\section{References}

1. Leibniz Institute of Plant Biochemistry. Energy for Chemical Barriers Central Carbon and Energy Metabolism of Trichomes Illuminated; IPB Press Release: Bogor, Indonesia, 2017; Available online: https:/ /www.ipb-halle.de/en/public-relations/news/article-detail/ energie-fuer-chemische-barrieren-auf-blatt-und-staengel/ (accessed on 15 November 2021).

2. Balcke, G.U.; Bennewitz, S.; Bergau, N.; Athmer, B.; Henning, A.; Majovsky, P.; Jiménez-Gómez, J.M.; Hoehenwarter, W.; Tissier A. Multi-Omics of Tomato Glandular Trichomes Reveals Distinct Features of Central Carbon Metabolism Supporting High Productivity of Specialized Metabolites. Plant Cell 2017, 29, 960-983. [CrossRef] [PubMed]

3. European Commission. Farm to Fork Strategy: For a Fair, Healthy and Environmentally-Friendly Food System; European Union: Brussels, Belgium, 2020; Available online: https:/ / ec.europa.eu/food/system/files/2020-05/f2f_action-plan_2020_strategy-info_ en.pdf (accessed on 30 October 2021).

4. Smith, V.; Wesseler, J.H.H.; Zilberman, D. New Plant Breeding Technologies: An Assessment of the Political Economy of the Regulatory Environment and the Implications for Sustainability. Sustainability 2021, 13, 3687. [CrossRef]

5. Wang, T.; Zhang, H.; Zhu, H. CRISPR technology is revolutionizing the improvement of tomato and other fruit crops. Hortic. Res. 2019, 6, 77. [CrossRef]

6. Sanatech Seed. Available online: https://sanatech-seed.com/en/211011-2 (accessed on 25 November 2021).

7. Cibus. Available online: https://www.cibus.com (accessed on 25 November 2021).

8. Beghin, J.C.; Gustafson, C.R. Consumer valuation of and attitudes towards novel foods produced with new plant engineering techniques: A review. Sustainability 2021, 13, 11348. [CrossRef]

9. Penn, J.M.; Hu, W. Understanding Hypothetical Bias: An Enhanced Meta-Analysis. Am. J. Agric. Econ. 2018, 100, 1186-1206. [CrossRef]

10. Lusk, J.L.; McFadden, B.R.; Wilson, N. Do consumers care how a genetically engineered food was created or who created it? Food Policy 2018, 78, 81-90. [CrossRef]

11. Muringai, V.; Fan, X.; Goddard, E. Canadian consumer acceptance of gene-edited versus genetically modified potatoes: A choice experiment approach. Can. J. Agric. Econ. 2020, 68, 47-63. [CrossRef]

12. Marette, S.; Disdier, A.-C.; Beghin, J.C. A comparison of EU and US consumers' willingness to pay for gene-edited food: Evidence from apples. Appetite 2021, 159, 105064. [CrossRef] [PubMed]

13. McFadden, B.R.; Smyth, S.J. Perceptions of Genetically Engineered Technology in Developed Areas. Trends Biotechnol. 2018, 37, 447-451. [CrossRef]

14. Carrasson, M.; Soler-Membrives, A.; Constenla, M.; Escobar, C.; Flos, R.; Gil, J.M.; Luzon, V.; Piferrer, F.; Reig, L. Information impact on consumers' perceptions towards aquaculture: Dismantling the myth about feeds for farmed fish. Aquaculture 2021, 544, 737137. [CrossRef]

15. Dolgopolova, I.; Teuber, R.; Bruschi, V.; Weber, G.-W.; Danilenko, N.; Galitskiy, E. Modelling consumer preferences for novel foods: Random utility and reference point effects approaches. In Modeling, Dynamics, Optimization and Bio-Economics II: DGS 2014; Proceedings in Mathematics and Statistics, Porto, Portugal, 17-21 February 2014; Pinto, A.A., Zilberman, D., Eds.; Springer: Cham, Switzerland, 2017; Volume 195, pp. 165-182.

16. Costa-Font, M.; Gil, J.M.; Traill, W. Consumer acceptance, valuation of and attitudes towards genetically modified food: Review and implications for food policy. Food Policy 2008, 33, 99-111. [CrossRef]

17. Boccaletti, S.; Moro, D. Consumer willingness-to-pay for GM food products in Italy. AgBioForum 2000, 3, $259-267$.

18. Scott, S.E.; Inbar, Y.; Wirz, C.D.; Brossard, D.; Rozin, P. An Overview of Attitudes toward Genetically Engineered Food. Annu. Rev. Nutr. 2018, 38, 459-479. [CrossRef] [PubMed]

19. Rollin, F.; Kennedy, J.; Wills, J. Consumers and new food technologies. Trends Food Sci. Technol. 2011, 22, 99-111. [CrossRef]

20. McFadden, B.R.; Lusk, J.L. Cognitive biases in the assimilation of scientific information on global warming and genetically modified food. Food Policy 2015, 54, 99-111. [CrossRef]

21. Yang, Y.; Hobbs, J.E. The power of stories: Narratives and information framing effects in science communication. Am. J. Agric. Econ. 2020, 102, 1271-1296. [CrossRef]

22. Grunert, K.G.; Bech-Larsen, T.; Lähteenmäki, L.; Ueland, Ø.; Åström, A. Attitudes towards the use of GMOs in food production and their impact on buying intention: The role of positive sensory experience. Agribusiness 2004, 20, 95-107. [CrossRef]

23. Kallas, Z.; Vitale, M.; Gil, J.M. Health Innovation in Patty Products. The Role of Food Neophobia in Consumers' Non-Hypothetical Willingness to Pay, Purchase Intention and Hedonic Evaluation. Nutrients 2019, 11, 444. [CrossRef] [PubMed]

24. Torquati, B.M.; Tempesta, T.; Vecchiato, D.; Venanzi, S. Tasty or Sustainable? The Effect of Product Sensory Experience on a Sustainable New Food Product: An Application of Discrete Choice Experiments on Chianina Tinned Beef. Sustainability 2018, 10, 2795. [CrossRef]

25. Bi, X.; Gao, Z.; Lisa, H.; Hausmann, D.S. Tradeoffs between sensory attributes and organic labels: The case of orange juice. Int. J. Consum. Stud. 2015, 39, 162-171. [CrossRef]

26. Akaichi, F.; Giha, C.R.; Glenk, K.; Gil, J.M. How Consumers in the UK and Spain Value the Coexistence of the Claims Low Fat, Local, Organic and Low Greenhouse Gas Emissions. Nutrients 2020, 12, 120. [CrossRef] [PubMed]

27. Ison, J.; Kontoleon, A. Consumer Preferences for Functional GM Foods in the UK: A Choice Experiment. AgBioForum 2014, 17, $28-36$. 
28. Costa-Font, M. Consumer Acceptance, Choice and Attitudes towards Genetically Modified (GM) Food. Ph.D. Thesis, Polytechnic University of Catalonia, Barcelona, Spain, February 2009. Available online: https://www.tdx.cat/bitstream/handle/10803/7059 /01jfmh01de01.pdf?sequence=1 (accessed on 10 October 2021).

29. Kontoleon, A.; Yabe, M. Assessing the impacts of alternative 'Opt-out' formats in choice experiment studies: Consumer preferences for genetically modified content and production information in food. J. Agric. Policy Res. 2003, 5, 1-43.

30. Veldwijk, J.; Lambooij, M.S.; de Bekker-Grob, E.W.; Smit, H.A.; de Wit, G.A. The Effect of Including an Opt-Out Option in Discrete Choice Experiments. PLoS ONE 2014, 9, e111805. [CrossRef] [PubMed]

31. Farid, M.; Cao, J.; Lim, Y.; Arato, T.; Kodama, K. Exploring Factors Affecting the Acceptance of Genetically Edited Food among Youth in Japan. Int. J. Environ. Res. Public Health 2020, 17, 2935. [CrossRef] [PubMed]

32. Sterns, J.A.; Schweikhardt, D.B.; Peterson, H.C. Using Case Studies as an Approach for Conducting Agribusiness Research. Int. Food Agribus. Manag. Rev. 1998, 1, 311-327. [CrossRef]

33. Mugera, A.W.; Bitsch, V. Managing Labor on Dairy Farms: A Resource-Based Perspective with Evidence from Case Studies. Int Food Agribus. Manag. Rev. 2005, 8, 79-98. [CrossRef]

34. Dörr, T. The Influence of Sensory Experience on Acceptance of CRSPR/Cas Tomatoes-Pilot Study. Master's Thesis, Martin Luther University Halle-Wittenberg, Halle, Germany, 2009.

35. Lombardi, G.V.; Berni, R.; Rocchi, B. Environmental friendly food. Choice experiment to assess consumer's attitude toward "climate neutral" milk: The role of communication. J. Clean. Prod. 2017, 142, 257-262. [CrossRef] 